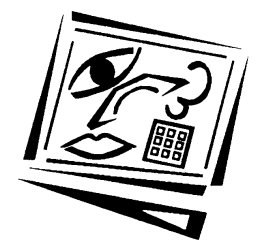

\title{
LMS transitioning to Moodle: A surprising case of successful, emergent change management
}

\begin{abstract}
University of Ballarat
During 2009-10 the University of Ballarat implemented the open source learning management system (LMS) Moodle alongside its existing legacy LMS, Blackboard. While previous IT implementations have been troublesome at the university, notably the student information and finance management systems in 2008-09, the Moodle implementation appears to have been a success. This article reviews the key factors in the implementation and points to several features which have made it a success. The success factors may be suitable for consideration by other organisations which are implementing change, particularly as several appear to run counter to the traditional conceptions of change and project management. This case study points to the importance of trust and empowerment of high quality LMS staff, who are focussed on the end-user rather than the technical side, to implement the project in an 'organic', emergent process. Given that the managerialist project management model, which appears to put more faith in systematic procedures than the staff who have to implement them, is more typical of many LMS and IT implementations, this case study revealed a surprising and refreshing level of approval for valuing staff expertise over 'tick box' adherence to technical checklists.
\end{abstract}

Alan Lawler

\section{Introduction}

The purpose of this case study was for the University's staff development department at the time, IPOL (Institute for Professional and Organisational Learning) to record, identify and analyse why the implementation of the Moodle learning management system (LMS) by a different university department at the time, LEWS (Learning Environments and Web Services) was considered to be a success at the University of Ballarat (UB) in the initial year of its implementation, 2010 [1]. The success of the implementation was attested to by many of the case study participants, the responsible Pro Vice-Chancellor at the time (University of Ballarat, IPOL Advisory Board Minutes, December 2010) and was characterised by one of the LMS staff's comment: "Moodle is a good news story" (Lawler, A., p.c., 23/6/2010).

While there is an extensive body of literature regarding implementations of LMS (Chao, 2008; Benson \& Palaskas, 2006; Birch \& Burnett, 2009; and Stewart, Briton, Gismondi, Heller, Kennepohl, McGreal \& Nelson, 2007 among others) the clear focus of the literature is on how to implement LMS in a technically proficient manner. While Benson and Palaskas (2006) acknowledge the human dimension in the application of the RIPPLES acronym (Resources, Infrastructure, People, Policies, Learning, Evaluation and Support, p. 550), the focus of the 'people' component is on the end users of the LMS, not the staff who conducted the implementation. From reviewing the literature it is this writer's view that most implementations adhere to Surry, Ensminger 
and Haab's (2005) contention that 'technology infrastructure is the single most important factor in integrating technology into the curriculum' (p. 328). Indeed these authors indicate that their study contradicted the 'prevailing wisdom that 'soft' factors... are the keys to successful technology integration' (p. 328).

This case study recasts the debate from the emphasis on the technical aspects of the implementation to the skill and expertise of the LMS staff who conduct the implementation. What made this case study interesting was that it put human beings, with our potential for personal depth and rich complexity, back into the "learning" part of the LMS. As the manager of LEWS at the time noted:

We had the right people at the right time... the particular skills of these three people [responsible for the implementation] are far and away the main reasons for the success [of the implementation]. (Lawler, A., p.c., 22/9/2010).

What made this case study so surprising was that trusting in the human aspects of the implementation, in an apparently laissez faire approach, worked more successfully than the previous managerialist, technocratic approaches had worked in the earlier student information and finance management systems implementations. Two comments from the fieldwork for the case study serve to illustrate this point:

\begin{abstract}
... the previous implementations had a technocratic emphasis, rather than a useremphasis. They hired technocrats [Manager of LEWS at the time]. (Lawler, A., p.c., 22/9/2010)

... the previous approach to the LMS by the support team was one of gatekeeper. Training was required before access and support was minimal because of the amount of time spent administering the system. With Moodle, the support team is far more able to visit academics, discuss requirements and construct solutions in a one-on-one fashion. I think this increases the perceived value of the system by tailoring the system to suit the academic' [LMS team member]. (Lawler, A., p.c., 23/6/2010).
\end{abstract}

\title{
A learning management system
}

A learning management system is defined as a software application that automates the administration, tracking and reporting of training events (Ellis, 2009). Ellis emphasises that a robust LMS should:

- Centralise and automate administration of training and learning

- Have capability for self-service and self-guided services

- Assemble and deliver learning content rapidly

- Consolidate training initiatives on a scalable web-based platform

- Support portability and standards

- Personalise content and enable knowledge re-use (p.1).

Luck, Jones, McConachie and Danaher (2004) define LMS as software systems specifically designed and marketed to educational institutions to support teaching and learning. They typically provide an electronic platform for upload of learning materials, student assessment, presentation of study material and organisation of student activities. These systems are also commonly referred to as virtual learning environments (VLE) and course management systems (CMS) (LEWS, 2009). 
For the University of Ballarat, the LMS was intended to become the primary vehicle for online learning and allow a greater range of functionality and reliability than the legacy LMS, Blackboard. In contrast to Blackboard, which has licensing payments for its proprietary software, Moodle is an "open source" LMS which means that it is free and available for download without license payments or other proprietary obligations. Ellis defines Moodle as a 'course management system' (CMS) used by educators rather than as a LMS for training and human resource management applications (p.4). In other words, Moodle was intended for use by teachers and academics in the preparation and teaching of their courses at UB.

Ellis (2009) noted that Moodle had a large and diverse user community with more than 330,000 registered users, speaking over 70 languages in 196 countries (p.4). Both Moodle and Blackboard were hosted on the University's IT servers, meaning that in-house expertise was required for the installation and maintenance of the software, including the inevitable upgrades, but avoiding the costs associated with having the provider host the LMS on the university's behalf.

An important feature of the Moodle program was that it allowed easy access from off campus locations, including uploading of teaching and learning materials by the lecturer and uploading of completed assignments by the students. Off campus access and reliability had been particularly difficult with the legacy LMS.

\section{The institutional context}

The University of Ballarat is a multi-sector university with its headquarters and main campuses in Ballarat, Victoria, Australia. The 'multi-sector' nature of the university includes 'UB Tec', comprising specialist courses for secondary school Years 11 and 12, Technical and Further Education (TAFE) which includes Certificate I to vocational degrees, and Higher Education, which includes studies at the degree and postgraduate coursework and research levels. In 2009, the University had 25,000 students of whom $45 \%$ were taught by the University's partner institutions around Australia and overseas. Approximately $45 \%$ of the University's students studied at one of the three Ballarat campuses while 9\% studied at one of the three western campuses at Stawell, Horsham and Ararat. The University had 250 TAFE teaching staff, 297 Higher Education academic staff and 621 general staff serving in both TAFE and Higher Education sections (University of Ballarat, 2009).

The University of Ballarat first adopted WebCT as its LMS in 2001 and, following the acquisition of WebCT by Blackboard in 2006, made the migration to Blackboard Campus Edition (CE) 6. To provide a snapshot of usage, a benchmark of content in Blackboard was conducted in December, 2008 and revealed 393 active courses in Higher Education and 144 active courses in TAFE (LEWS, 2009, p.9).

The above profile suggests that a LMS that demonstrated high quality and reliable off campus access was essential to the university's teaching and learning activities. While the partner institutions were originally intended to be included in the implementation, beginning with a trial at one Melbourne location in 2010, the partners were not involved in the implementation throughout 2009-10. At the time of writing, the intention is for the partners to be included in the future. Given the percentage of student teaching conducted through partner institutions and the complexities of Ballarat-based teaching staff coordinating and moderating multiple classes in the same 
subject at different locations around Australia and overseas, off campus access and reliability for partner providers was an important consideration of the LMS for UB. A feature of Moodle which had appeal particularly in relation to partners was its ability to manage groups, an aspect of software functionality specific to managing subjects at different locations.

\section{Method of the case study}

The writer, at the time a senior manager of the former IPOL, was commissioned by the Pro Vice-Chancellor of Learning and Quality to investigate and write a case study regarding the implementation of Moodle at the University over 2009-10. As the case study was constructed from the opinions and viewpoints of various staff members and university students, the review was conducted using a qualitative methodology and included interviews and analysis of primary and secondary sources. The eight interviewees were identified using the 'snowball' technique (Glesne \& Peshkin, 1992) and involved seven university staff and two students, one studying in Higher Education and one in TAFE. The university staff included two LMS officers and the department manager of LEWS who were responsible for the implementation of the project across the university. The remaining four participants were a flexible learning technology officer in the TAFE area and three users of Moodle responsible for teaching: two TAFE teachers and one Higher Education academic.

The review of primary source material included the LEWS LMS report of September, 2009 which was presented to the Vice-Chancellor's Senior Team for discussion and approval. Secondary sources of information included the comments from five academic staff who were video-recorded for inclusion in the LEWS submission for a Vice-Chancellor's Award at UB in 2010. Other sources of information included numerous meetings and discussions over a twelve month period beginning in December, 2009 with an IPOL Advisory Board meeting. A number of university staff have informally provided information and been available for questioning throughout the case study investigation. Table 1 summarises the sources for used for the case study.

Table 1: Sources for the case study, 2009-10

\begin{tabular}{|l|l|l|}
\hline \multicolumn{1}{|c|}{ Source } & \multicolumn{1}{|c|}{ Participants/materials } & \multicolumn{1}{c|}{ Mode of research } \\
\hline University of Ballarat staff & $\begin{array}{l}\text { 2 LMS officers in Higher } \\
\text { Education } \\
\text { 1 LEWS manager } \\
\text { 1 LMS officer in TAFE } \\
\text { 3 end-users of Moodle: 2 in TAFE, } \\
\text { 1 academic in Higher Education }\end{array}$ & In-person interviews \\
\hline University of Ballarat student & 1 student in TAFE & Phone interview \\
\hline University documents & $\begin{array}{l}\text { LEW LMS report of September, } \\
\text { 2009 }\end{array}$ & Analysis of written report \\
\hline & $\begin{array}{l}\text { LEWS submission for the 2010 } \\
\text { Vice-Chancellor's Award at UB }\end{array}$ & $\begin{array}{l}\text { Analysis of video recorded } \\
\text { interviews and commentary } \\
\text { from 5 academic staff } \\
\text { regarding the implementation }\end{array}$ \\
\hline & $\begin{array}{l}\text { Review of the December, 2010 } \\
\text { IPOL Advisory Board Minutes }\end{array}$ \\
\hline Board meeting & Review of informal discussions \\
\hline $\begin{array}{l}\text { Informal discussions with } \\
\text { university staff and students }\end{array}$ & Several staff and students & \\
\hline
\end{tabular}




\section{Background to the implementation}

\section{8-2009}

During 2008 a LMS staff member conducted extensive research on the extent of use, user friendliness and effectiveness of the contemporaneous LMS, Blackboard in the light of the expiration of the Blackboard contract in early 2011 (LEWS, University of Ballarat, 2009). This legacy LMS was found to have significant technical and usability issues along with a low rate of use and, significantly, a low rate of high-intensity use. At the same time early adopters of Moodle within the University were advocating the adoption of Moodle as the University's LMS.

The LMS staff member conducted an evaluation of a range of LMSs and an intensive trial of Moodle with one keenly interested academic in early 2009. The LMS staff member went on to conduct two online surveys, one with staff $(n=20)$ and one with students $(n=270)$ and a series of focus groups with both staff and students to enable graphing of responses to a range of typical LMS functionality questions. The results of the online surveys and focus groups indicated a strong preference for Moodle by staff and a positive, although less strong, preference from students. While the staff strongly favoured several of Moodle's features such as automated course/ unit creation, autoenrolment of students into the course/ unit and compatibility with most web browsers, students seemed less interested in any particular LMS other than it should be easy to use, easy to send files to and from any location (e.g. uploading assignments) and able to function with most web browsers and on most computers.

Following the trial of Moodle in 2009 the LMS staff member conducted a second round of online surveys with both staff $(n=21)$ and students $(n=155)$ regarding their experience as users. The results tended to mirror the earlier online surveys with both staff and students favouring Moodle with staff endorsing it more strongly.

During the later stages of 2009 a discussion paper and final report were submitted to the senior management group of the University with a range of recommendations and issues for consideration. Issues raised in the reports included the importance of clarifying the service levels required and expected by various stakeholders, cost of the implementation including training and de-commissioning of the legacy LMS, available and potential infrastructure and resource support for the implementation of the new LMS within the University.

\section{0-2011}

Throughout 2010 both LMSs operated concurrently with extensive training conducted in Moodle and an ever-growing number of users within the University. Throughout 2010 and into early 2011 a total of 144 teaching staff/lecturers were trained in Moodle, including 29 from TAFE. Of the total number trained, only one quarter were already active users of Blackboard. During the period of the migration from Blackboard to Moodle 248 training sessions were offered across five modules from 'Getting Started' to 'Multimedia' and 'Groups and Groupings' (Lawler, A., p.c. 7/10/2011). It appeared that Moodle had 'sold' itself and academic staff were using an LMS, and using it more fully, than had been the case with Blackboard. The Blackboard installation was decommissioned in December, 2010 with a several-month grace period which allowed for the completion of migration to Moodle as the University's sole LMS by early 2011. 
As noted above, the kind of training that has been conducted with the Moodle implementation throughout 2010 has not been the standard model of IT training that requires a comprehensive, technical user manual and a linear format of content training. The training has provided a set of notes and resources for each of the typical uses of Moodle such as communicating with students, assessment, content expansion options and the management of several classes at different locations for the same course/unit. Along with many of the non-traditional aspects of this implementation the training has been focussed on the user's needs, not the software's capabilities and limitations. The difference in emphasis has, to this observer, been an important part of the implementation's success. Table 2 provides an outline of the LMS implementation over the years 2008-2011.

Table 2: Outline of the LMS implementation

\begin{tabular}{|l|l|l|l|}
\hline \multicolumn{1}{|c|}{2008} & \multicolumn{1}{|c|}{2009} & \multicolumn{1}{c|}{2010} & \multicolumn{1}{c|}{2011} \\
\hline $\begin{array}{l}\text { LMS staff review of } \\
\text { current LMS, } \\
\text { Blackboard CE 6: total of } \\
\text { 537 active courses } \\
\text { across Higher } \\
\text { Education and TAFE. }\end{array}$ & $\begin{array}{l}\text { Trial of Moodle with 1 } \\
\text { academic. }\end{array}$ & $\begin{array}{l}\text { Continuation of } \\
\text { Two rounds of online } \\
\text { surveys regarding LMS } \\
\text { preferences. } \\
\text { offered on voluntary } \\
\text { basis. }\end{array}$ & $\begin{array}{l}\text { All Higher Education } \\
\text { and TAFE staff and } \\
\text { students use Moodle as } \\
\text { sole LMS. }\end{array}$ \\
& $\begin{array}{l}\text { Round 1: 20 staff and } \\
\text { 270 students; } \\
\text { Round 2: 21 staff and } \\
\text { 155 students } \\
\text { offered in 5 key Moodle } \\
\text { modules; 144 teaching } \\
\text { staff trained, approx } \\
\text { one-quarter previously } \\
\text { active users of } \\
\text { Blackboard. }\end{array}$ & \\
& $\begin{array}{l}\text { LEWS final report with } \\
\text { recommendations } \\
\text { forwarded to Vice- } \\
\text { Chancellor's Senior } \\
\text { Team. }\end{array}$ & $\begin{array}{l}\text { December: Blackboard } \\
\text { officially decommissio- } \\
\text { ned (with grace period } \\
\text { into semester 1, 2011). }\end{array}$ & \\
\hline
\end{tabular}

\section{Discussion}

\section{Emergent change: An alternative to orthodox project management}

Mintzberg (1987, 1994) and Mintzberg and Quinn (1998) provide an interesting and quite different approach to the issues of strategic implementations in organisations. The orthodox assumption of those involved in conducting a large scale implementation is that it will proceed according to the "scientific" model of traditional project management with timelines, approved budgets and specified accountabilities. Most importantly, the orthodox assumption is that the implementation will proceed in a linear and controllable fashion. This assumption has evolved from Lewin's (1947) highly influential model of change, which suggests that organisational change occurs in a three-step process labelled as 'unfreeze-change-refreeze' (p. 34). The 'unfreeze' step connotes the deconstruction of the prevailing forces that have held previous practices in place, while the 'refreeze' step connotes the reinforcement of the newly implemented practices. As Lewin (1947) noted, the nature of the 'change' itself is the subject of much debate (Lawler \& Sillitoe, 2010; Morrison \& Milliken, 2000). Such a linear model of change is implicit in much of the literature in relation to LMS implementations (Chao, 2008; Benson \& Palaskas, 2006; Birch \& Burnett, 2009). Indeed, Stewart et al (2007) specify that their recommended new LMS (coincidentially, Moodle) 'ought to be introduced within a controlled and coherent framework' (p. 3). 
Mintzberg (1987) de-bunks the linear view of strategy, as he de-bunked the traditional view of what managers actually do (1990). Mintzberg (1987) proposes an "emergent" view of strategy whereby the multitudinous range of issues, which occur concurrently, are acknowledged and wrestled with. Rather than a linear model, Mintzberg proposes a model that looks more like a stream of competing, occasionally conflicting and sometimes coalescing factors which combine with the 'deliberate' strategy to form the 'realised strategy' (p. 14). The 'realised strategy' in this context is the implementation of the LMS. According the Mintzberg, the factors constituting the organisational environment in which the implementation will occur inter-relate and affect each other, just as Senge (2006) proposed in his systems view of organisational learning. Both Mintzberg (1987) and Senge (2006) view organisational change as an intersecting set of factors which affect each other as they are operationalised. From the emergent change viewpoint, the atomistic and linear model of Lewin's unfreeze-change-refreeze mode is limited in its applicability given the complexity and unpredictability of a 'realised strategy' such as a LMS implementation. This case study supported the 'emergent change' view of realised strategy and organisational change as suggested by Mintzberg (1987) and Senge (2006).

Turning to the case study itself, several factors have been identified as reasons for the implementation's success, some of which run counter to the conventional wisdom about effective management (Taylor, 2003; Mintzberg, 1990). As implied from the above discussion, while traditional managers would have us believe change is effectively managed from the top down with lashings of planning, organising, coordinating and controlling (Samson \& Daft, 2009) the insights from this case study reveal that it may have been successful partially because these purported management virtues were not particularly influential or even evident. This is the "surprise" suggested in the title of this article. Normally LMS and other IT implementations would necessitate adherence to strict project methodology and therefore have applicability for other large scale corporate implementations. This was not the case with this implementation. The fact that the implementation did not meet traditional expectations was what made it of note to the case study participants, the writer and to many in the university. It was so surprising that the Pro Vice-Chancellor with overall responsibility for the implementation commissioned the case study. The case study, albeit limited in scope and number, established that having valuable and credible LMS staff was more relevant to the implementation's success than the adherence to the strictures of traditional project management.

More recent change management literature (Morrison \& Milliken, 2000; Hiatt, 2006; Lawler \& Sillitoe, 2010) suggest that change is implemented more effectively when those implementing the change have ownership over the process and that regular line employees, in this case the LMS staff in addition to end users, are meaningfully engaged in the process before and during the implementation. These features were evident in this case study as illustrated by the following comments:

... the constant focus groups and the time that we spent interacting with staff showed that we were listening and not just pushing a product. [LMS team member] (Lawler, A., p.c., $23 / 6 / 2010)$.

... we focussed on tasks and end-users rather than project documentation and reporting. We haven't set any targets for usage - let the academics move across as they want: we don't have mandated timeframes. [LMS team member] (Lawler, A., p.c., 21/7/2010). 
From the two TAFE end users of Moodle: "We have been offered lots of support but management made it very clear it's 'your problem' to solve". (Lawler, A., p. c., $24 / 8 / 2010)$.

These comments suggest that the LMS implementation team were highly focussed on the needs of their end users, rather than the technical specifications of the LMS and that the end users had responsibility for the implementation at their work location.

It is interesting to note that, somewhat contrary to traditional expectations, aspects of the implementation which may have contributed to its success were that:

- Communication from the senior executive group regarding authorisation of the project was apparently unclear to staff involved with the implementation, meaning they were not sure when and to what extent the project was authorised.

- It was not constrained by implementation within a relatively short time frame.

- It was not beholden to the strictures of project management methodology, particularly in terms of adherence to frequent reporting.

- It was not required to meet certain targets of usage by certain dates.

Other factors which contributed to the implementation's success, as reported by both the LEWS report (2009) and the case study participants, were that:

- The new system was strongly favoured as easier to use and more reliable than the legacy system, particularly by staff users.

- All staff users of the new system in 2010 did so on a voluntary basis with students within that particular course/ unit therefore expected to use Moodle.

- The relatively low number of high intensity users of the legacy LMS meant that there wasn't a strong psychological and organisational investment in it.

- There was extensive and effective training in the new system that was not implemented in the traditional manner. Instead the training provided a set of resources relevant for particular user issues such as communication to students, assessment, content expansion with things like podcasts and online forums, and managing groups of classes and locations for the one course/unit.

- The LMS staff involved with the project maintained a focus on end users and were determined to meet needs and fix any problems to make the system usable. The LMS implementation and training staff were determined to deliver what they said they would deliver.

While it may be understood from the above point, it was clear that the LMS staff themselves were not only of high quality technically but also of great skill in human interaction and communication. They showed that they were able to relate to the concerns users raised. This implementation was not a case of the 'geeks' ruling and the masses having to suffer an IT implementation that they could barely understand, let alone use. The project staff related well to people, not just technology. The following quote illustrates the LMS staff's commitment to understanding the needs of the users:

I tried to ignore the technical side of the implementation and focus on finding solutions that would benefit staff, as far as ease of use and with an aim to lower workloads. (Lawler, A., p.c., 23/6/2010).

While it is easy to attribute the success of the Moodle implementation in 2010 to the voluntary nature of adoption and its greater ease of use and reliability than the legacy 
system, the unconventional aspects of the emergent implementation processes are of great interest. The LMS and academic literatures are replete with exhortations about stringent project management methodology and management accountability (Birnbaum, 2000; Analoui, 2007). As seen earlier, this implementation was noteworthy for the lack of expected managerialist and project management processes.

\title{
Confounding project management: Few timelines, no approved budget
}

The fieldwork for this case study uncovered an awareness in the management of LEWS in early 2008 of the legacy LMS's limitations and the prospect of contract renewal at the end of 2010. Despite the sense of required action that this timeline would suggest, there was a perception among staff of a surprisingly lengthy period of inertia in various levels of the organisation. For example, while a definitive report with recommendations and costings regarding the Moodle trial was submitted to the senior executive group at the end of 2009, a clear authority regarding budget and staffing was not given to the LMS manager and staff into 2010. Indeed, the decision to proceed with the implementation of Moodle in 2010 was made within LEWS management and without a budget approved by senior management. This appears to run counter to Siemens' (2006) review of LMS reviews which listed 'skirting senior management' (p.3) as one of the LMS purchasing mistakes to avoid. While it is tempting to ask how action without explicit senior management approval could occur, it is the contention of this paper that the lack of centralised decision making and hierarchical communication aided the higher level of ownership by the LMS team. As the manager of LEWS at the time noted:

\begin{abstract}
As a manager I encourage good people skills; I'm open to questions, ideas and am an empowering manager. I build a team culture that is positive and inclusive. I make sure they've got resources and get out of their way. I'm essentially a bit of an anarchist: I'm not keen on project management methodology (Lawler, A., p.c. 22/9/2010).
\end{abstract}

The above quote indicates a level of devolution of responsibility by the LEWS manager to the LMS staff which engendered empowerment among his/her staff.

The change management model advocated by Hiatt (2006), which suggests that the ADKAR (Awareness, Desire, Knowledge, Ability, Reinforcement) method is an optimal model of change management, is supported by the results of this case study. ADKAR highlights the centrality of the empowerment of people in change management. Certainly the first four stages of the ADKAR model were present throughout the trial in 2009 and implementation in 2010.

The following section outlines how the Moodle implementation mirrored the first four steps of the ADKAR model. 'A' - awareness: there was a high level of awareness of other LMS options by the LMS staff and a significant level of LMS usage among teaching staff through their use of Blackboard CE6. As noted in the LEWS (2009) report, there were over 390 Higher Education and 140 TAFE active courses in Blackboard in December, 2008 and over 40 staff and 420 students who participated in the LMS focus groups in 2009. These results suggest that there was a widespread awareness that the university was moving towards a more fully integrated and higher intensity use of elearning. The training provided in Moodle throughout 2010 continued to raise awareness of the importance and practice of learning management systems on behalf of both teaching staff and students. ' $\mathrm{D}$ ' - desire: there was a desire by the teaching staff and students for a better LMS than Blackboard that had functionality for, among other 
things, inclusion of podcasts, download of audiovisual files and upload of assignments from off campus. As the TAFE student interviewed for the case study said:

I was using Blackboard and (the teacher) suggested using Moodle. It was fun, good and I learnt something ... Moodle was much faster and more interactive, it explained things better. My other classes on Blackboard were all text-based and Moodle is more interactive: you get to do things with it. I found it really helpful. (Lawler, A. p.c., 28/9/2010).

The next two elements of the ADKAR acronym, ' $\mathrm{K}$ ' - knowledge and 'A' - ability are relevant to the emergent change implementation model raised by this case study. There was a high degree of knowledge and ability by the LMS staff in how to adapt the system to user needs. As noted previously, not only were the LMS staff technically competent but they were also driven by the motivation to make the system usable for staff and students. As one of the LMS team members interviewed for the case study said:

My objective from the start was to support staff, make changes and training to assist them in their adoption of the system ... I believe that if I simplify the system, address the needs of the academics, then the student will benefit indirectly. The student was the priority from the start and was the key reason that Moodle was chosen over its competitors. (Lawler, A., p.c. 23/6/2010).

The final element of the ADKAR acronym, $\mathrm{R}$ - reinforcement, parallels Lewin's (1947) 're-freeze' component of the linear model of change. As this case study was conducted during the year of voluntary adoption of Moodle, 2010, it was not possible to ascertain the degree to which 'reinforcement' of the change to Moodle had resulted in a settled and successful usage of the new LMS. A direction for future research could include a revisited case study of the implementation of Moodle at UB. Such a follow up case study could include the degree to which the 'forced migration' to Moodle in 2011 resulted in a successful level of reinforcement according to the ADKAR model.

\section{Contra-indications: Limitations of emergent change management?}

While the bulk of this paper has argued in favour of an emergent model of change management and a high level of trust and empowerment of the LMS implementation staff, it should be noted that there were some problems with the implementation. Given the multitudinous factors involved in any LMS implementation, it is not surprising that not everything went smoothly. Of particular relevance to the emergent model of change was the apparent lack of systematic, coordinated communication among university staff who were not involved in the pilot test in 2009 or voluntary adoption process in 2010. The academic end user interviewed for the case study said:

... when Moodle was endorsed with notice that Blackboard will shut down, Blackboard users were furious; they were very annoyed and ill-informed. They were really rolling content from Blackboard to Moodle and people outside the trial were not kept in the loop. People who were out of the loop felt disengaged and threatened. (Lawler, A., p.c., $30 / 9 / 2010)$.

It is clear that systematic and coordinated communication is required for a successful implementation, particularly for users of the legacy system.

Another problem raised by the switch to Moodle was the far higher use of Internet download by students which resulted in them quickly using their university Internet quota. As the TAFE student said for the case study: 
It turned out I was downloading Moodle DVDs instead of Blackboard text and used up all my Internet download time. I was flat out on it but I didn't mind, I had to watch DVDs in the classroom and on Moodle at home was better ... but it did end up blowing up. (Lawler, A., p.c. 28/9/2010).

Clearly a review of student Internet download quotas was required in advance of the change from text-based LMS use with Blackboard CE6 to audiovisual use with Moodle.

It is easy to argue that these two issues, communication and student download quotas, were predictable concerns that should have been addressed in the project implementation. They suggest a potential weakness of relying solely on the emergent change process. It is reasonable to suggest that a blend of emergent change and traditional project management would make for the most effective approach to an LMS implementation.

\section{Conclusion}

The greater ease of use and functionality of Moodle, along with the voluntary nature of adoption in 2010, were undeniable factors in its early success. However, the process of the implementation, which this article suggests followed an emergent model of change management, also contributed to its success. The decision to implement the trials in 2009, the high calibre of the LMS staff who focussed on the needs of the users rather than the technical side of the implementation, and the training and implementation during 2010, were made within the LEWS group and without an approved budget. These factors suggest a high level of local ownership and empowerment with an implementation that could potentially affect all teaching and learning at the University.

While the apparent lack of definitive authority regarding budget and staff was reported as frustrating by the LEWS staff (Lawler, A., p.c., 23/6/2010 \& 21/7/2010), it may be that the localised decision making and greater staff ownership, practices extolled in more modern models of management (Hiatt, 2006; Morrison \& Milliken, 2000), were effective.

There were many surprises in this case study: that an apparently laissez faire approach to project management worked, that having high calibre LMS staff was at least equally as important as the specifics of the technology and that emergent change appears to have a place in LMS implementations. For this writer, who finds that traditional project management sits uneasily with the complexities of organisational life and is silent on the level of expertise competent staff bring to their work, the success of an emergent change management approach has been uplifting. Given the Byzantine nature of decision making in universities (Lawler \& Sillitoe, 2010) perhaps such an emergent change process, with its far higher level of empowerment of relevant staff, should be more frequently encouraged.

\section{Endnotes}

1. The key LMS staff emphasised that the implementation was not completed in 2010 as the legacy LMS, Blackboard, was still available to UB staff throughout that year. Blackboard was de-activated at the end of 2010, although technically still available into the first teaching semester of 2011. 


\section{References}

Analoui, F. (2007). Strategic human resource management. UK: Thomson Learning.

Benson, R. \& Palaskas, T. (2006). Introducing a new learning management system: An institutional case study. Australasian Journal of Educational Technology, 22(4), 548-567. http:/ / www.ascilite.org.au/ajet/ajet22/benson.html

Birch, D. \& Burnett, B. (2009). Bringing academics on board: encouraging institution-wide diffusion of e-learning environments. Australasian Journal of Educational Technology, 25(1), 117134. http:/ / www.ascilite.org.au/ajet/ ajet25/birch.html

Birnbaum, R. (2000). Management fads in higher education. USA: Jossey-Bass.

Chao, I. T. (2008). Moving to Moodle: Reflections two years later. EDUCAUSE Quarterly, 31(3), 4652. http:/ / net.educause.edu/ir/library/pdf/EQM0837.pdf

Ellis, R. (2009). A field guide to learning management systems. USA: American Society of Training and Development (ASTD).

Glesne, C. \& Peshkin, A. (1992). Becoming qualitative researchers: An introduction. White Plains, NY: Longman.

Hiatt, J. (2006). ADKAR. A model for change in business, government and our community. USA: Prosci.

Lawler, A. \& Sillitoe, J. (2010). Perspectives on instituting change management in large organisations. Australian Universities' Review, 52(2), 43-48. http: / / archimedes.ballarat.edu.au:8080/vital/access/HandleResolver/1959.17 / 26220

Lewin, K. (1947). Frontiers in group dynamics: Concept, method and reality in social science; social equilibria and social change. Human Relations, 1(5), 5-41. http: / / dx.doi.org/10.1177/001872674700100103

LEWS (2009). Learning Management System Review: Final Report. Learning Environments and Web Services, University of Ballarat, Ballarat, Victoria, Australia. http: / / medusa.ballarat.edu.au / wordpress / moodle / files / 2009/11/lms-review-report-final.PDF

Luck, J., Jones, D., McConachie, J. \& Danaher, P. (2004). Challenging enterprises and subcultures: Interrogating 'best practice' in Central Queensland University's course management systems. Studies in Learning, Evaluation, Innovation and Development, 1(2), 19-31. http: / / sleid.cqu.edu.au/viewarticle.php?id=33

Mintzberg, H. (1987). The strategy concept 1: five Ps for strategy. California Management Review, Fall, 11-24.

Mintzberg, H. (1990). The manager's job: Folklore and fact. Harvard Business Review, 68(2), 163176.

Mintzberg, H. (1994). The rise and fall of strategic planning. UK: Prentice Hall.

Mintzberg, H. and Quinn, J. (Eds), (1998). Readings in the strategy process. USA: Prentice Hall.

Morrison, E. \& Milliken, F. (2000). Organizational silence: A barrier to change and development in a pluralistic world. The Academy of Management Review, 25(4), 706-725. http://www.jstor.org/pss/259200

Samson, D. \& Daft, R. (2009). Management, 3rd Asia Pacific Edition. South Melbourne: Cengage Learning Australia. 
Senge, P. (2006). The fifth discipline: The art and practice of the learning organization. London: Random House.

Siemens, G. (2006). Learning or management systems? A review of learning management system reviews. Learning Technologies Centre, University of Manitoba. October 6.

Stewart, B., Briton, D., Gismondi, M., Heller, B., Kennepohl, D., McGreal, R. \& Nelson, C. (2007). Choosing Moodle: an evaluation of learning management systems at Athabasca University. International Journal of Distance Education Technologies, 5(3), 1-7.

Surry, D., Ensminger, D. \& Haab, M. (2005). A model for integrating instructional technology into higher education. British Journal of Educational Technology, 36(2), 327-329. http: / / dx.doi.org/10.1111/j.1467-8535.2005.00461.x

Taylor, F. (2003). Scientific management. e-Book, London, UK: Routledge.

University of Ballarat (2009). UB pocket statistics, 2009. University of Ballarat, Ballarat, Victoria, Australia. http://guerin.ballarat.edu.au/docs/pocket_stats_09.pdf

University of Ballarat (2010). IPOL Advisory Board Minutes, November. University of Ballarat, Ballarat, Victoria, Australia.

Author: Alan Lawler, Lecturer, School of Business

The University of Ballarat, PO Box 663, Ballarat VIC 3353

Email: a.lawler@ballarat.edu.au

Please cite as: Lawler, A. (2011). LMS transitioning to Moodle: A surprising case of successful, emergent change management. Australasian Journal of Educational Technology, 27(7), 1111-1123. http://www.ascilite.org.au/ajet/ ajet27/lawler.html 